\title{
BMJ Open Acute Exacerbation and Respiratory Infections in COPD (AERIS): protocol for a prospective, observational cohort study
}

\author{
Simon Bourne, ${ }^{1}$ Catherine Cohet, ${ }^{2}$ Viktoriya Kim, ${ }^{1}$ Anna Barton, ${ }^{1}$ Andy Tuck, ${ }^{3}$ \\ Emmanuel Aris, ${ }^{2}$ Sonia Mesia-Vela, ${ }^{2}$ Jeanne-Marie Devaster, ${ }^{2}$ W Ripley Ballou, ${ }^{2}$ \\ Stuart Clarke, ${ }^{3,4}$ Tom Wilkinson ${ }^{5,6}$
}

To cite: Bourne S, Cohet C, Kim V, et al. Acute

Exacerbation and Respiratory Infections in COPD (AERIS): protocol for a prospective, observational cohort study. BMJ Open 2014:4:e004546. doi:10.1136/bmjopen-2013004546

- Prepublication history for this paper is available online. To view these files please visit the journal online (http://dx.doi.org/10.1136/ bmjopen-2013-004546).

Received 24 November 2013 Revised 12 February 2014 Accepted 13 February 2014

CrossMark

For numbered affiliations see end of article.

Correspondence to Dr Tom Wilkinson; T.Wilkinson@soton.ac.uk

\section{ABSTRACT}

Introduction: The aetiology of acute exacerbations of chronic obstructive pulmonary disease (COPD) remains incompletely understood and strategies for treatment and prevention have not altered significantly for many years. Improved understanding of the role of respiratory pathogens in acute exacerbations of COPD (AECOPD) is required and the use of molecular microbiological techniques may lead to insights into host-pathogen interactions and the development of more targeted therapeutic approaches.

Methods and analyses: Acute Exacerbation and Respiratory Infections in COPD (AERIS) is a longitudinal epidemiological study to assess how changes in the COPD airway microbiome contribute to the incidence and severity of AECOPD. Patients with COPD aged $40-85$ are followed monthly for 2 years, and reviewed within $72 \mathrm{~h}$ of onset of symptoms of AECOPD. Exacerbations are detected using daily electronic diary cards. Blood, sputum, nasopharyngeal and urine samples are collected at prespecified timepoints. Molecular diagnostic and typing techniques are used to describe the dynamics of airway infection during $\mathrm{AECOPD}$ and stable disease, and associations with clinical outcome. This study aims to refine the case definition of AECOPD to reflect the possible microbiological aetiology. AERIS will assess the impact of AECOPD on health-related quality of life and healthcare resource utilisation, and the possible interactions between nutritional status, infection and immune responses.

Ethics and dissemination: AERIS is conducted in accordance with the Declaration of Helsinki and Good Clinical Practice, and has been approved by the institutional ethics and review board. All participants must provide written informed consent. The results obtained will be disseminated at international medical conferences and in peer-reviewed publications.

Discussion: Few other studies have addressed the complexity of the microbiological and systemic components of COPD or employed real-time electronic tracking of symptoms to identify AECOPD and potential aetiological triggers.

Results: Results of AERIS will increase our understanding of the contribution of pathogens to

\section{Strengths and limitations of this study}

Conducted in a specialised hospital that has extensive experience in respiratory research.

- Comprehensive assessment of clinical status, microbiology, functional status, nutritional status, health-related quality of life and healthcare resource utilisation in individual patients in a single large cohort during stable chronic obstructive pulmonary disease (COPD) and acute exacerbations of COPD (AECOPD).

- AECOPD are proactively identified through patient-completed electronic diaries.

- Cohort retention is a key factor in the successful delivery of such a study and with in-depth sampling protocols, participant engagement, comfort and feedback are key factors in optimising cohort retention and comprehensive data collection.

AECOPD, potentially leading to new targeted therapeutic and preventative interventions.

Trial registration number: ClinicalTrials.gov NCT01360398.

\section{INTRODUCTION}

Chronic obstructive pulmonary disease (COPD) is an inflammatory disease of the lung, characterised by progressive airflow limitation that is not fully reversible. ${ }^{1}$ COPD is the most common chronic respiratory illness in older adults, affecting an estimated 210 million people worldwide. ${ }^{2}$ This condition has a substantial impact on quality of life. $^{2}$ The Global Burden of Disease Study found COPD to be the third leading cause of death globally and the ninth leading cause of years of life lost due to premature mortality in $2010,{ }^{3}$ accounting for $3.7 \%$ of years lived with disability and $3.1 \%$ of disability-adjusted 
life years worldwide. ${ }^{45}$ COPD also imposes a substantial socioeconomic burden. In 2001, the total cost of COPD in Europe was reported to be $€ 38.7$ billion. ${ }^{6}$

Considerable progress has been made concerning the epidemiology, pathophysiology and clinical management of COPD in recent years. However, significant challenges remain. Improved understanding of acute exacerbations of COPD (AECOPD) is a key research priority. AECOPD are highly relevant clinically, being a major cause of COPD-related morbidity and mortality, ${ }^{7-11}$ as well as accounting for a substantial proportion of the significant social, healthcare and economic burden of COPD. ${ }^{6}$ It has been estimated that AECOPD account for approximately $70 \%$ of total healthcare costs associated with COPD. ${ }^{12}$ Patients with Global Initiative for Chronic Obstructive Lung Disease (GOLD) stage II disease or greater experience one or two exacerbations annually. Exacerbation varies from patient to patient with severity of disease. ${ }^{13}$ Various triggers for AECOPD have been identified $^{1}$; however, up to $75 \%$ of all exacerbations are associated with the detection of bacterial and/or viral respiratory pathogens. ${ }^{1415}$ Exacerbations associated with detectable respiratory pathogens have been shown to have a more marked impact on lung function and longer duration of hospitalisation than exacerbations of non-infectious aetiology. ${ }^{14}$

With the introduction of new molecular sequencing techniques, the traditional belief that healthy lungs are sterile has been refuted. There is increasing evidence that the lower respiratory tract contains a diverse microbial flora that differs between health and disease. ${ }^{16-20}$ The presence of potentially pathogenic microorganisms in the inflamed airways of patients with COPD is well documented, with up to $50 \%$ of patients with stable COPD showing evidence of lower airway bacterial colonisation using traditional culture techniques. ${ }^{15} 2122 \mathrm{In}$ patients with COPD, bacterial detection in lower airway derived samples is associated with increased airway inflammation, reduced lung function and more frequent exacerbations. ${ }^{23-25}$ Acquisition of new pathogen strains also appears to be associated with an increased risk of AECOPD. ${ }^{15} 21{ }^{26}$ Estimates of the relative contribution of different pathogens to AECOPD vary. However, non-typeable Haemophilus influenzae appears to be the major bacterial pathogen associated with AECOPD, followed by Streptococcus pneumoniae, Moraxella catarrhalis and Pseudomonas aeruginosa. ${ }^{14}{ }^{15}$ Respiratory viruses commonly associated with AECOPD are diverse and include human rhinoviruses, influenza and parainfluenza viruses, respiratory syncytial virus, coronavirus and adenovirus. ${ }^{15}$

Improved understanding of the role of infectious pathogens in AECOPD is required to better understand the pathophysiology of the disease and may lead to the development of more targeted strategies for treatment and prevention. This article describes the objectives and design of Acute Exacerbation and Respiratory Infections in COPD (AERIS), a prospective longitudinal epidemiological study initiated in the UK to assess the role of respiratory infection in AECOPD. Molecular diagnostic and typing techniques will be used to describe the dynamics of airway infection and its potential association with clinical outcome. The study will also assess the impact of AECOPD on health-related quality of life and healthcare resource utilisation, as well as the possible interaction between disease endotype and exacerbations.

\section{OBJECTIVES}

The primary objective of the AERIS study is to estimate the incidence of all-cause AECOPD and of AECOPD with sputum containing bacterial pathogens (overall and by species). Secondary study objectives are summarised in table 1.

\section{METHODS}

\section{Study design}

This is an ongoing, single-centre, prospective, observational cohort study based at University Hospital Southampton, UK.

Table 1 Overview of primary and secondary objectives of the AERIS study

\begin{tabular}{|c|c|}
\hline Level & Objective \\
\hline Primary & $\begin{array}{l}\text { To estimate the incidence rate of all-cause } \\
\text { AECOPD } \\
\text { To estimate the incidence rate of AECOPD } \\
\text { having sputum containing bacterial } \\
\text { pathogens (overall and by species) }\end{array}$ \\
\hline Secondary & $\begin{array}{l}\text { To describe the proportion of overall and } \\
\text { specific bacterial pathogens detected in } \\
\text { sputum by severity of AECOPD } \\
\text { To describe the proportion of overall and } \\
\text { specific bacterial pathogens detected in } \\
\text { sputum in stable COPD } \\
\text { To estimate the incidence rate of AECOPD } \\
\text { having sputum containing viral pathogens } \\
\text { (overall and by species) } \\
\text { To describe the proportion of overall and } \\
\text { specific viral pathogens detected in sputum } \\
\text { by severity of AECOPD } \\
\text { To estimate the time elapsed between } \\
\text { consecutive AECOPD episodes } \\
\text { To assess the impact of all-cause } \\
\text { AECOPD and stable COPD on } \\
\text { health-related quality of life } \\
\text { To assess the impact on healthcare use: } \\
\text { - Of all-cause AECOPD } \\
\text { - Of AECOPD having sputum containing } \\
\text { bacterial pathogens } \\
\text { - Of AECOPD having sputum containing } \\
\text { viral pathogens }\end{array}$ \\
\hline
\end{tabular}

AECOPD, acute exacerbations of chronic obstructive pulmonary disease; AERIS, Acute Exacerbation and Respiratory Infections in COPD. 


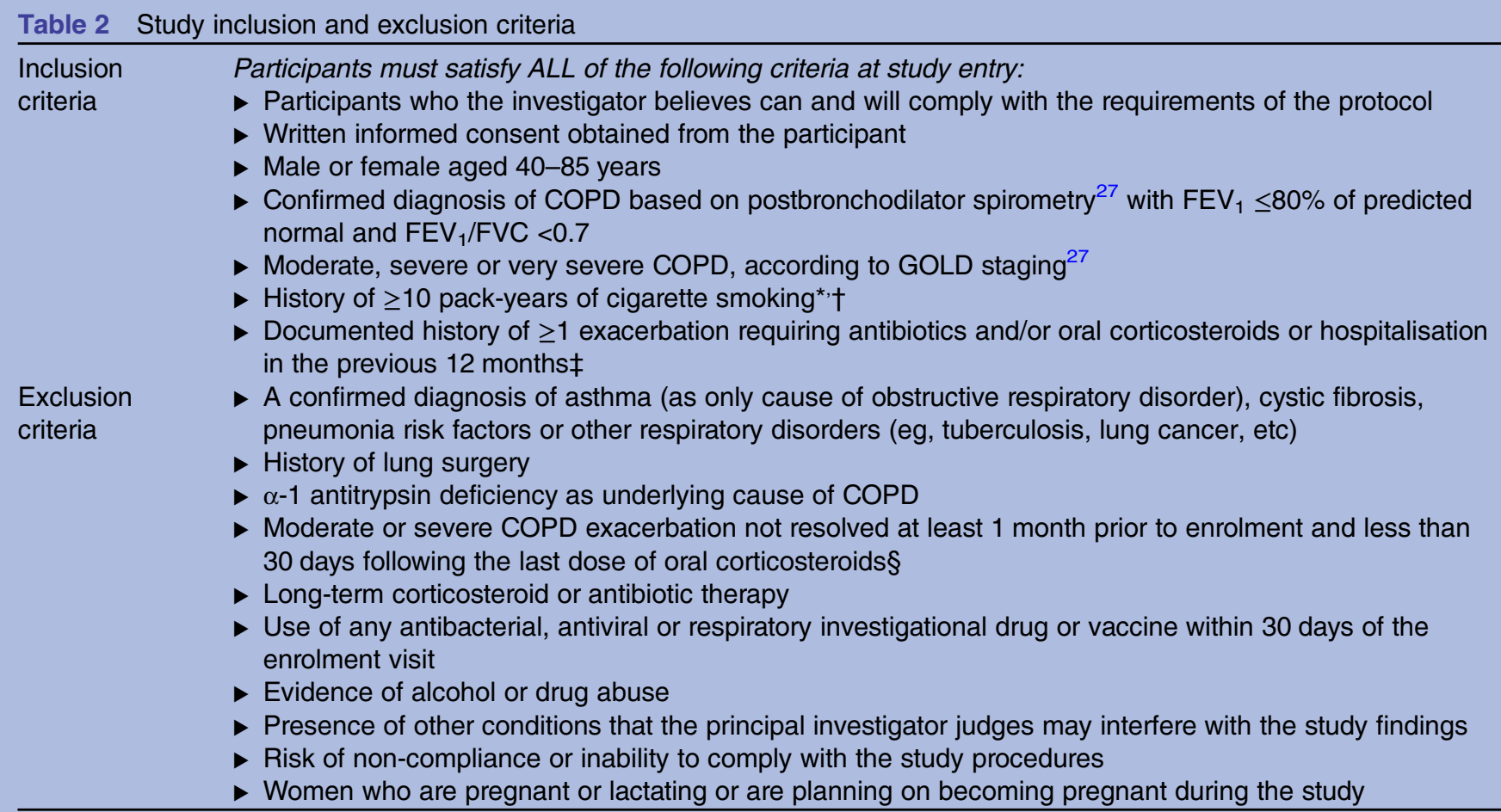

${ }^{*}$ Former smokers are defined as those who have stopped smoking for at least 6 months.

†Number of pack years=(number of cigarettes per day/20) $\times$ number of years smoked.

$\ddagger$ Participants with recent COPD exacerbations, in stable condition, and having stopped antibiotics, can be enrolled 1 month postexacerbation. $\S$ Participants can be enrolled when their AECOPD or pneumonia has resolved.

AECOPD, acute exacerbations of chronic obstructive pulmonary disease; FEV ${ }_{1}$, forced expiratory volume in $1 \mathrm{~s}$; FVC, forced vital capacity; GOLD, Global Initiative for Chronic Obstructive Lung Disease.

\section{Study population}

Male and female patients with COPD between the age of 40 and 85 years are eligible for study participation provided they meet the following inclusion criteria: (1) a confirmed diagnosis of COPD with postbronchodilator forced expiratory volume in $1 \mathrm{~s}\left(\mathrm{FEV}_{1}\right) \leq 80 \%$ of the predicted normal value and $\mathrm{FEV}_{1} /$ forced vital capacity $(\mathrm{FVC}) \leq 0.7$, consistent with GOLD stage II-IV disease $\mathrm{e}^{27}$ (2) current or ex-smoker with smoking history $\geq 10$ packyears and (3) one or more documented exacerbations of COPD treated with antibiotics and/or steroids in the 12 months prior to enrolment (table 2). Participants with recent COPD exacerbations, in stable condition and having stopped antibiotics, can be enrolled 1-month postexacerbation. Exclusion criteria include other known respiratory conditions, such as asthma, as the only cause of the respiratory obstructive disorder, $\alpha-1$ antitrypsin deficiency, cystic fibrosis, tuberculosis, lung cancer, history of lung surgery and other conditions imposing pneumonia risk. Participants on long-term corticosteroid or antibiotic therapy at the time of enrolment and those who received antibiotics and/or steroids in the month prior to the enrolment were also excluded.

\section{Clinical data collection}

Participants are seen for an enrolment visit and then monthly for 2 years. Regular review of medications and, when required, changes to medical therapy and active smoking cessation advice are performed according to standard clinical practice at each visit. In addition to these scheduled visits, all participants are seen in the clinic within $72 \mathrm{~h}$ (3 days) of onset of symptoms of AECOPD. AECOPD is defined as worsening of at least two major symptoms (dyspnoea, sputum volume and sputum purulence) or worsening of at least one major symptom and one minor symptom (wheeze, sore throat, cold (nasal discharge and/or nasal congestion), cough and fever (oral temperature $>37.5^{\circ} \mathrm{C}$ ) without other cause),${ }^{28}$ considered clinically relevant at the site. Exacerbations are identified by means of electronic diary cards that participants complete daily. The data recorded daily in the electronic diary cards include self-performed peak flow measurement (peak expiratory flow (PEF) and $\mathrm{FEV}_{1}$ ), a series of morning questions to identify symptoms of exacerbations ${ }^{29}$ and the EXAcerbations of Chronic Pulmonary Disease Tool V.1.0 (EXACT-PRO) at bedtime. Participants are also asked to record any changes to their usual treatment. Data on patient-reported symptoms based on morning questions and on $\mathrm{PEF} / \mathrm{FEV}_{1}$ are transmitted daily to the study clinic. Changes/worsening in these symptoms are monitored by the study staff and participants are contacted and invited to the clinic when an exacerbation is suspected.

\section{Study procedures}

In addition to the daily monitoring undertaken through the patient-completed electronic diary cards, a wide 
Table 3 Overview of study assessments performed at the scheduled monthly visits and at exacerbation visits

\begin{tabular}{|c|c|}
\hline Description & Frequency of assessment* \\
\hline \multicolumn{2}{|l|}{ Clinical variables } \\
\hline Physical examination & Monthly and within $72 \mathrm{~h}$ of onset of exacerbation \\
\hline Anthropometrics and nutritional screening (MUST) $\dagger$ & Quarterly \\
\hline Intercurrent comorbidities & Monthly and within $72 \mathrm{~h}$ of onset of exacerbation \\
\hline Medical history/medical record review & Study entry and within $72 \mathrm{~h}$ of onset of exacerbation \\
\hline Vaccination history & Annually \\
\hline Current medication & Monthly \\
\hline Smoking status & Monthly \\
\hline Urine pregnancy test & Study entry, final visit and within $72 \mathrm{~h}$ of onset of exacerbation \\
\hline Chest CT scan & Study entry and final visit \\
\hline Chest X-ray & Within $72 \mathrm{~h}$ of onset of exacerbation \\
\hline \multicolumn{2}{|l|}{ Lung function testing } \\
\hline Body box & Study entry and final visit \\
\hline TLCO $\ddagger$ & Every 6 months and within $72 \mathrm{~h}$ of onset of exacerbation \\
\hline Spirometry & Monthly and within $72 \mathrm{~h}$ of onset of exacerbation \\
\hline 6 min walk test & Every 6 months \\
\hline \multicolumn{2}{|l|}{ Questionnaires and patient-reported outcome instruments } \\
\hline $\begin{array}{l}\text { ATS-DLD-78A (risk factors, disease history and } \\
\text { smoking history) }\end{array}$ & Study entry \\
\hline Healthcare use & Monthly and within $72 \mathrm{~h}$ of onset of exacerbation \\
\hline mMRCף & Every 6 months \\
\hline CAT questionnaire ${ }^{* *}$ & Quarterly and within $72 \mathrm{~h}$ of onset of exacerbation \\
\hline EQ-5D index and VASt† & Quarterly and within $72 \mathrm{~h}$ of onset of exacerbation \\
\hline NEADL $\ddagger \ddagger$ & Quarterly and within $72 \mathrm{~h}$ of onset of exacerbation \\
\hline CNAQ§§ & Quarterly and within $72 \mathrm{~h}$ of onset of exacerbation \\
\hline \multicolumn{2}{|l|}{ Biological specimen collection } \\
\hline \multicolumn{2}{|l|}{ Blood sampling } \\
\hline For routine biochemistry & Study entry \\
\hline For cell-mediated immune response & Quarterly and within $72 \mathrm{~h}$ of onset of exacerbation \\
\hline For biomarkers, blood counts and haematology & Quarterly and within $72 \mathrm{~h}$ of onset of exacerbation \\
\hline For RNA transcript profiling & Every 6 months and within $72 \mathrm{~h}$ of onset of exacerbation \\
\hline For vitamins, antioxidants and nutrients $(20 \mathrm{~mL})$ & Every 6 months and within $72 \mathrm{~h}$ of onset of exacerbation \\
\hline Nasopharyngeal swab samplingףी & Monthly and within $72 \mathrm{~h}$ of onset of exacerbation \\
\hline Sputum sampling & Monthly and within $72 \mathrm{~h}$ of onset of exacerbation \\
\hline Breath sampling*** & Monthly and within $72 \mathrm{~h}$ of onset of exacerbation \\
\hline Urine sampling††† & Monthly and within $72 \mathrm{~h}$ of onset of exacerbation \\
\hline \multicolumn{2}{|c|}{ 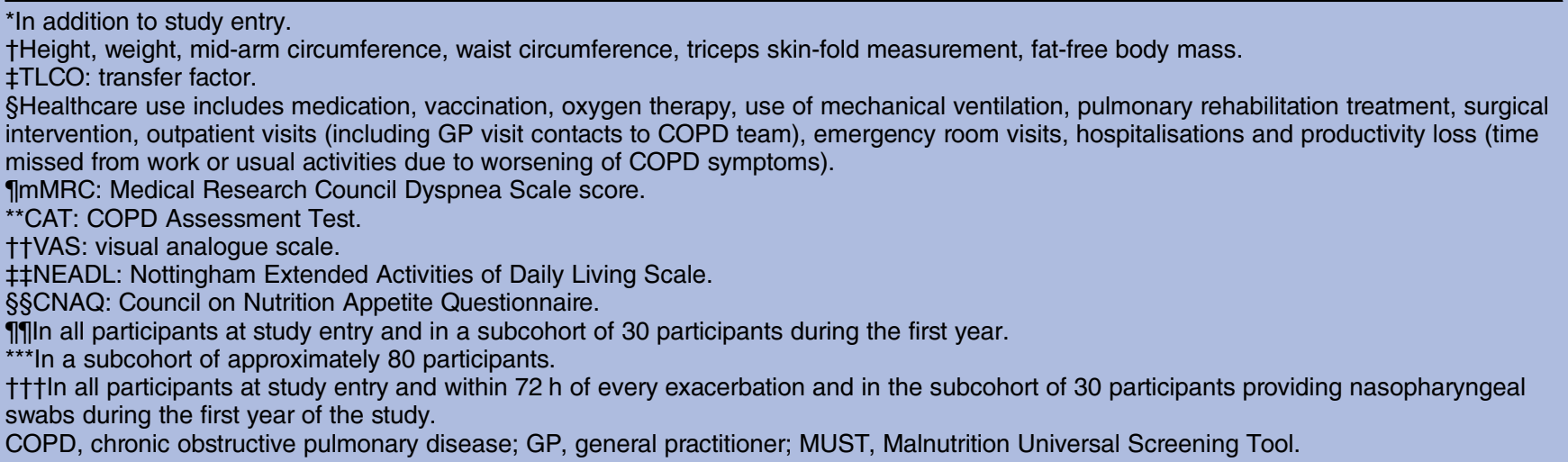 } \\
\hline
\end{tabular}

range of study procedures are performed at study entry, scheduled monthly visits and exacerbation visits (table 3 ).

\section{Clinical assessments}

Quantitative high-resolution CT scans are performed at enrolment and study conclusion to describe the degree of bronchiectasis and emphysema noted and to exclude other acute or evolving lung pathologies besides COPD and sequelae of COPD. A physical examination is performed at all visits. Medical history, smoking status and details of medication use are updated monthly. Influenza and pneumococcal vaccination status is updated annually.

Lung function testing is performed using spirometry, body plethysmography (lung volumes, body box) and single breath diffusion (gas transfer, transfer factor 
(TLCO)) at specified visits. The following outcomes are recorded: spirometry, $\mathrm{FEV}_{1}, \mathrm{FVC}, \mathrm{FEV}_{1} / \mathrm{FVC}$ ratio, $\mathrm{FEV}_{1} \%$ predicted, mid-expiratory flow between $25 \%$ and $75 \%$ of the FVC (MEF25-75), single breath diffusion (TLCO and rate of carbon monoxide uptake (KCO) and body plethysmography (total lung capacity (TLC), residual volume (RV), vital capacity and RV/TLC). At the enrolment visit, participants are asked to refrain from using short-acting bronchodilators for at least $6 \mathrm{~h}$ and long-acting bronchodilators for at least $12 \mathrm{~h}$ before key procedures. Prior to the subsequent follow-up visits, participants may use their usual medication normally. Lung function measurements are performed under controlled conditions and in the sitting position as per standard practice.

Anthropometrics (including but not restricted to height, weight, waist and mid-arm circumference and triceps skin-fold circumference) are measured quarterly. Grip strength and fatigability are measured using standard techniques. Anthropometric data are used to compute the Malnutrition Universal Screening Tool (MUST) score. $^{30}$ Nutritional information (including planned/unplanned weight loss and history and changes in food intake patterns) is collected quarterly according to MUST guidelines.

A posteroanterior chest X-ray (and lateral if required) is performed at all exacerbation visits, as per standard clinical practice, in order to rule out pneumonia.

\section{Questionnaires and patient-reported outcome instruments}

Various outcomes are assessed quarterly and at exacerbation using a series of questionnaires and patientreported outcome instruments, such as the COPD Assessment Test (CAT), ${ }^{31}$ the Nottingham Extended Activities of Daily Living (NEADL) Scale, ${ }^{32}$ the Council on Nutrition Appetite Questionnaire (CNAQ) ${ }^{33}$ and the EQ-5D. ${ }^{34}$ The five items included in the EQ-5D index are mobility, self-care, usual activities, pain/discomfort and anxiety/depression. The BODE index (Body-Mass Index, Degree of Airflow Obstruction, Level of Functional Dyspnoea, Exercise Capacity ${ }^{35}$ will also be calculated.

Healthcare use is recorded at all visits, including medication, vaccination, oxygen therapy, use of mechanical ventilation, pulmonary rehabilitation treatment, surgical intervention, outpatient visits (including general practitioner visits and telephone contacts to COPD team), emergency room visits, hospitalisations and productivity loss (time missed from work or usual activities due to worsening of COPD symptoms). Potential changes in disease management following an exacerbation (eg, change in medication use) are also recorded.

\section{Biological specimen collection}

A wide range of biological specimens are collected from study participants (table 3). Blood samples are collected from all patients at study entry, quarterly and at exacerbation. Sputum samples are obtained by spontaneous expectoration or induced by stimulation according to standard methods from all patients at study entry, monthly and at exacerbation. Nasopharyngeal swabs are collected from all patients at study entry and then from a subcohort of 30 patients at monthly follow-up visits and at exacerbation during the first year of follow-up. Urine samples are collected from all patients at study entry and at exacerbation and from the subcohort of 30 patients at monthly follow-up visits during the first year. Breath samples are collected from approximately 80 patients (including the subcohort of 30 patients providing nasopharyngeal swabs) at monthly follow-up visits and at exacerbation visits during the first year.

Blood samples are analysed for disease-related biomarkers, biochemistry, cell-mediated immune response, RNA profile and nutrients. Sputum samples are processed by traditional culture techniques and multiplex PCR analysis for identification of potential respiratory pathogens (including, but not limited to, non-typeable $H$ influenzae, $M$ catarrhalis, $S$ pneumoniae, $P$ aeruginosa, Staphylococcus aureus, respiratory syncytial virus, parainfluenza virus, rhinovirus, human metapneumovirus, influenza virus, adenovirus and coronavirus). Sputum samples may also be analysed for disease-related biomarkers. Nasopharyngeal swabs are processed by traditional culture techniques and multiplex PCR analysis for potential pathogen identification. Urine samples may be processed for disease-related biomarkers. Breath samples are analysed by the selected ion flow tube mass spectrometry for identification of volatile organic compounds that may be characteristic for AECOPD.

Laboratory assays are performed at the Public Health Laboratory of Public Health England at University Hospital Southampton Foundation National Health Service (NHS) Trust, GlaxoSmithKline (GSK) Vaccines central laboratory and other GSK Vaccines designated laboratories. The assays use standardised and validated procedures. Aliquots of all biological samples are processed (if applicable), frozen and stored for possible further disease-related testing. Culture isolates are also stored. Any additional laboratory tests will be performed at a GSK designated laboratory.

\section{Sample size calculation}

The sample size calculation was based on the primary study endpoint of incidence of all-cause AECOPD. Assuming that, on average, each participant is observed for a period of 18 months and that two episodes of AECOPD can be expected per participant per year, if 120 participants are followed, the number of total person-years would be around 180 and during this time around 360 exacerbation events would be detected. If the distribution of events per participant follows a Poisson distribution with no overdispersion, an overdispersion factor of 1.5 , or an overdispersion of 2 , the approximate values of the lower and upper bounds of the $95 \% \mathrm{CI}$ around the point estimate of two events per participant per year would be 1.8-2.2, 1.7-2.3 and 1.7- 
2.3, respectively. So a sample size of 120 participants should ensure sufficient precision in the estimation of the incidence rate of all-cause AECOPDs.

Additionally, in order to follow 120 participants effectively, given the fact that participants may be eligible but withdraw quite early in the study possibly due to the deterioration of the participant's health, the decision was taken to replace participants who withdrew during the first year of follow-up, and recruit additional participants.

We will construct a CONSORT diagram and capture where possible reasons for screen failure, dropouts and loss to follow-up.

\section{Data analysis}

The primary study endpoints are the occurrence of allcause AECOPD and the occurrence of AECOPD having sputum containing bacterial pathogens as detected by culture (overall and by species). The proportion of participants at each visit for whom a sputum sample was obtained will be computed; overall and by the method the samples were obtained (spontaneous or induced). The proportion of sputum samples obtained at each visit and positive for specific bacterial pathogens (overall and by bacterial species) will also be calculated. The incidence rate of all-cause AECOPD and of AECOPD having sputum containing bacterial pathogens (overall and by bacterial species) will be calculated, with $95 \%$ CI. The 95\% CI of the incidence rate will be computed using a model which accounts for repeated events, namely the generalised linear model assuming a negative binomial distribution for the response variable with logarithm as link function, and the logarithm of time for follow-up as an offset variable as a preliminary approach. Other flexible approaches to statistical analysis may also be used. In addition, the same model with covariates (eg, smoking status at enrolment, number of moderate/ severe exacerbations reported in the 12 months prior to enrolment, presence of respiratory pathogenic bacteria detected at the exacerbation visit and at previous visits) will be applied. Incidence rates will also be calculated for moderate AECOPD and for severe AECOPD.

\section{DISSEMINATION}

All participants must provide written informed consent to participate.

AERIS is being conducted in a specialised hospital that has extensive experience in respiratory research. AECOPD are proactively identified through patientcompleted electronic diaries. After confirmation by phone, symptoms of an exacerbation trigger a clinic visit within $72 \mathrm{~h}$ of symptom onset to enable comparisons of samples from same patient in stable COPD and during AECOPD. Although this is an intensive study with prolonged follow-up, patients are expected to benefit from the improved access to expert care.
The results obtained will be disseminated by presentations at international medical conferences and peerreviewed publications. Reporting will be in accordance with STROBE guidance.

\section{DISCUSSION}

The AERIS study has been initiated to comprehensively assess the role of infectious pathogens in AECOPD in a well-characterised cohort of patients. The study aims to explore the dynamics of airway infection and its possible contribution to AECOPD, as well as the potential role of chronic colonisation in stable disease. The overall objective of the study will aim at refining the case definition of AECOPD to reflect the possible microbiological aetiology of exacerbations. This is of note, since there is currently no commonly agreed definition of AECOPD and no current case definition includes a microbiological endpoint. The impact of AECOPD on health-related quality of life and healthcare use will be assessed in order to provide a complete picture of disease burden. The interaction between airway infection and systemic manifestations of COPD and nutritional status will also be assessed in detail for the first time. Biological specimens collected during the study may also be used for further disease-related testing, including molecular typing to describe and compare selected biomarkers in AECOPD and stable COPD, to explore cell-mediated immune response to specific bacterial antigens, and to develop non-invasive bacterial diagnostic methods.

To our knowledge, few other studies have employed real-time electronic tracking of symptoms to identify AECOPD and potential aetiological triggers. This is important since available data suggest that up to $50 \%$ of exacerbations may not be reported to healthcare providers and consequently exacerbation rates are lower in studies employing event-based criteria to define AECOPD. ${ }^{36}$ Due to the close daily monitoring of symptoms to identify AECOPD, we anticipate that the exacerbation rate in this study will be higher than previously reported. This close monitoring and early therapeutic intervention at exacerbation may also impact on estimates of the overall burden of disease.

A number of other epidemiological studies have been initiated in recent years to further characterise our understanding of the natural history of AECOPD. However, it is important to recognise that most of these studies have not included molecular microbiological assessments. Recent large observational studies focusing on biomarker discovery have involved close phenotyping of patients with COPD, but have not studied the aetiology of exacerbations in depth. ${ }^{37-39}$ In another study, potentially pathogenic bacterial strains were identified using molecular typing techniques, although viruses as potential airway pathogens were not investigated. ${ }^{21}$ More recently, the prevalence and load of airway bacteria in stable and exacerbated AECOPD have been assessed in paired samples from 52 patients participating in the London COPD cohort study using modern 
molecular techniques. ${ }^{19}$ Airway bacterial prevalence and load was found to increase significantly during AECOPD, with quantitative molecular techniques proving more discriminatory than culture. However, assessment was limited to only the three most commonly detected airway bacteria ( $H$ influenzae, $S$ pneumoniae and $M$ catarrhalis). However, other potential pathogens and the overall respiratory microbiome may also contribute and have not yet been studied in detail. ${ }^{17} 18204041$ In AERIS, samples will be acquired during AECOPD and stable disease and analysed for a wide range of potentially pathogenic bacteria and viruses using advanced PCR-based techniques as well as traditional culture-based methods.

A major strength of the AERIS study design is the comprehensive assessment of clinical status, microbiology, functional status, nutritional status, health-related quality of life and healthcare resource utilisation in individual patients in a single large cohort during stable COPD and AECOPD. The selection of participants with a history of at least a single exacerbation enriches the cohort to some degree and ensures an adequate number of exacerbations are sampled. It is accepted that some aspects of the analysis may not be generalisable to the subgroup of patients who never exacerbate. The analyses proposed in this study will generate epidemiological data to complement that derived from existing COPD cohorts and further explore determinants of COPD and the contribution of bacterial and viral pathogens to AECOPD, as well as to provide some understanding of the limitations of existing data. As exacerbation visits are triggered by patient diary data, accurate and timely diary completion is essential. All participants in this study receive diary training at enrolment and support is available from the study team at all times to promote accurate and complete diary keeping. Cohort retention is a key factor in the successful delivery of such a study and with in-depth sampling protocols, participant engagement, comfort and feedback are key factors in optimising cohort retention and comprehensive data collection.

Identification of novel approaches for the prevention of AECOPD is an important research goal. Long-acting $\beta$-agonists (LABA) and long-acting antimuscarinic bronchodilators remain the cornerstone of treatment for patients with COPD. ${ }^{42}$ Combinations of LABA and inhaled corticosteroids are also used in patients with more severe disease and/or frequent exacerbations. Long-term treatment with macrolide antibiotics and pulsed quinolone therapy may be considered for exacerbation prevention. ${ }^{73}{ }^{44}$ However, concerns exist about the potential for development of antimicrobial resistance during long-term antibiotic therapy. Numerous other approaches are under investigation for the prevention of AECOPD, including anti-inflammatory drugs, immunomodulatory agents, immunotherapy, antioxidants and non-pharmacological strategies. Vaccination is another potential approach meriting investigation for reducing AECOPD risk. However, optimal strategies targeting key respiratory pathogens are not yet available to the clinician.
In conclusion, there have been considerable advances in our understanding of the epidemiology, pathophysiology and clinical management of COPD in recent years. However, there remains a genuine need to further explore the aetiology and pathogenesis of AECOPD. It is anticipated that results of this epidemiological study will increase our understanding of the contribution of bacterial and viral pathogens to AECOPD, the natural history of these events in association with the timing of symptoms and physiological changes, and will offer new direction for research into targeted therapeutic and preventative interventions.

\section{Author affiliations}

${ }^{1}$ Department of Respiratory Medicine, University Hospitals Southampton NHS Foundation Trust, Southampton, UK

${ }^{2}$ GlaxoSmithKline Vaccines, Rixensart, Belgium

${ }^{3}$ Infectious Disease Epidemiology Group, Sir Henry Wellcome Laboratories, Academic Unit of Clinical and Experimental Sciences, Faculty of Medicine, University of Southampton, Southampton, UK

${ }^{4}$ Public Health England, Southampton, UK

${ }^{5}$ Academic Unit of Clinical and Experimental Sciences, Faculty of Medicine, University of Southampton, Southampton, UK

${ }^{6}$ Southampton NIHR Respiratory Biomedical Research Unit, University Hospital Southampton Foundation NHS Trust, Southampton, UK

Acknowledgements The authors wish to thank the patients with chronic obstructive pulmonary disease and their carers who are participating in this study. They also wish to acknowledge the support of the Southampton National Institute for Health Research (NIHR) Wellcome Trust Clinical Research Facility (CRF) the Southampton NIHR Biomedical Research Centre (BRC) and the NIHR Southampton Respiratory Biomedical Research Unit (RBRU). The CRF, BRC and RBRU are funded by NIHR and are a partnership between the University of Southampton and University Hospital Southampton NHS Foundation Trust (UHS). The authors also acknowledge Kerry Gove (University of Southampton) for lung function measurements, Dr Tony Williams (University of Southampton) for cell-mediated immunity sample capture, Dr Steve Wootton and Kesta Durkin (UHS) for nutritional assessments, Dr Stephen Harden (UHS) for supervision of CT scanning and Sister Lindsay Welch (UHS) for leading the nursing team. The authors also thank local patient groups, including the British Lung Foundation Breathe Easy groups, for their continued support. The authors would also like to acknowledge the GlaxoSmithKline (GSK) Vaccines study team: Sylvia Taylor (epidemiology team), Pascale Lallemand and Rosalia Calamera (data management), Marcela Gavigan (clinical operations), Seona McGregor and Rebecca White (local support), Silvia Damaso and Maxim Blum (statistical support), Peter Vink (input in the design) and Marie-Josée Uwamahoro. They also thank Jennifer Coward (independent writer on behalf of GSK Vaccines) for scientific writing support and Wouter Houthoofd (XPE Pharma and Science, on behalf of GSK Vaccines) for publication coordination.

Contributors SB closely involved in all steps of the study and specifically wrote substantial parts of the protocol. CC was responsible for this observational study and was closely involved in the design of study. VK and $A B$ closely involved in the conduct of this study. AT was involved in writing of microbiology parts of the protocol. EA was responsible for writing of statistical analysis plan and definition of statistical outcomes. SMV closely involved in the discussion on design and follow-up of the study. J-MD closely involved in all discussions. WRB closely involved in all discussions of design of this study. SC closely involved in all steps of the study. TW involved in all steps of the study. All authors provided intellectual input into the development of this manuscript, and have critically reviewed and approved the final version of the manuscript.

Funding GSK Biologicals SA funded this study and paid for all costs associated with the development and publishing of the manuscript.

Competing interests $\mathrm{SB}, \mathrm{VK}, \mathrm{AB}, \mathrm{AT}, \mathrm{SC}$ and TW received an institutional grant from GSK group of companies to conduct this study. SB reports 
receiving grants, advisory board fees and assistance in attending conferences from GSK. He has also received fees for lecturing, advisory boards and teaching from Novartis, AstraZeneca and Boehringer Ingelheim. SC has also received project grant support, conference funding attendance and advisory board payments from Pfizer, GSK and Novartis (all payments were made to employing institution). TW has also received travel expenses, fees for advisory boards GSK related to this study, fees for advisory boards from Pfizer and AstraZeneca, reimbursement for travel and conference attendance from Boehringer Ingelheim, consultancy fees from Almirall, and financial support from Novartis and Retroscreen (travel expenses, consultancy and project support costs). CC, EA, SMV, J-MD and WRB are employed by GSK; CC, EA, J-MD and WRB also report GSK stock options.

Ethics approval The AERIS (Acute Exacerbation and Respiratory Infections in COPD) study is conducted in accordance with the Declaration of Helsinki and Good Clinical Practice guidelines, and has been approved by the relevant institutional ethics and review board and the Southampton Ethics Board.

Provenance and peer review Not commissioned; externally peer reviewed.

Open Access This is an Open Access article distributed in accordance with the Creative Commons Attribution Non Commercial (CC BY-NC 3.0) license, which permits others to distribute, remix, adapt, build upon this work noncommercially, and license their derivative works on different terms, provided the original work is properly cited and the use is non-commercial. See: http:// creativecommons.org/licenses/by-nc/3.0/

\section{REFERENCES}

1. Decramer M, Janssens W, Miravitlles M. Chronic obstructive pulmonary disease. Lancet 2012;379:1341-51.

2. Bousquet J, Kiley J, Bateman ED, et al. Prioritized research agenda for prevention and control of chronic respiratory diseases. Eur Respir J 2010;36:995-1001.

3. Lozano R, Naghavi M, Foreman K, et al. Global and regional mortality from 235 causes of death for 20 age groups in 1990 and 2010: a systemic analysis for the Global Burden of Disease Study 2010. Lancet 2012;380:2095-128.

4. Vos T, Flaxman AD, Lozano R, et al. Years lived with disability (YLDs) for 1160 sequelae of 289 diseases and injuries 1990-2010: a systemic analysis for the Global Burden of Disease Study 2010. Lancet 2012;380:2163-96.

5. Murray CJ, Vos T, Lozano R, et al. Disability-adjusted life years (DALYs) for 291 diseases and injuries in 21 regions, 1990-2010: a systemic analysis for the Global Burden of Disease Study 2010. Lancet 2012;380:2197-223.

6. Loddenkemper R, Gibson GJ, Sibbille Y. European Respiratory Society/European Lung Foundation. European lung white book. The first comprehensive survey on respiratory health in Europe. Sheffield England: European Respiratory Society Journals Ltd, 2003.

7. Seemungal TA, Wilkinson TM, Hurst JR, et al. Long-term erythromycin therapy is associated with decreased chronic obstructive pulmonary disease exacerbations. Am J Respir Crit Care Med 2008;178:1139-47.

8. Donaldson GC, Seemungal TA, Bhowmik A, et al. Relationship between exacerbation frequency and lung function decline in chronic obstructive pulmonary disease. Thorax 2002;57:847-52.

9. Miravitlles M, Ferrer M, Pont A, et al. Effect of exacerbations on quality of life in patients with chronic obstructive pulmonary disease: a 2 year follow up study. Thorax 2004;59:387-95.

10. Soler-Cataluña JJ, Martínez-García MA, Román-Sánchez $\mathrm{P}$, et al. Severe acute exacerbations and mortality in patients with chronic obstructive pulmonary disease. Thorax 2005;60:925-31.

11. Nishimura K, Sato S, Tsukino M, et al. Effect of exacerbations on health status in subjects with chronic obstructive pulmonary disease. Health Qual Life Outcomes 2009;7:69.

12. Sullivan SD, Ramsey SD, Lee TA. The economic burden of COPD. Chest 2000;117(2 Suppl):5S-9S.

13. Hurst JR, Vestbo J, Anzueto A, et al. Susceptibility to exacerbation in chronic obstructive pulmonary disease. $N$ Engl J Med 2010;363:1128-38.

14. Papi A, Bellettato CM, Braccioni F, et al. Infections and airway inflammation in chronic obstructive pulmonary disease severe exacerbations. Am J Respir Crit Care Med 2006;173:1114-21.

15. Sethi S, Murphy TF. Infection in the pathogenesis and course of chronic obstructive pulmonary disease. N Engl J Med 2008;359:2355-65.

16. Hilty $\mathrm{M}$, Burke $\mathrm{C}$, Pedro $\mathrm{H}$, et al. Disordered microbial communities in asthmatic airways. PLoS ONE 2010;5:e8578.
17. Huang YJ, Kim E, Cox MJ, et al. A persistent and diverse airway microbiota present during chronic obstructive pulmonary disease exacerbations. OMICS 2010;14:9-59.

18. Erb-Downward JR, Thompson DL, Han MK, et al. Analysis of the lung microbiome in the "healthy" smoker and in COPD. PLOS ONE 2011;6:e16384.

19. Garcha DS, Thurston SJ, Patel AR, et al. Changes in prevalence and load of airway bacteria using quantitative PCR in stable and exacerbated COPD. Thorax 2012;67:1075-80.

20. Pragman AA, Kim HB, Reilly CS, et al. The lung microbiome in moderate and severe chronic obstructive pulmonary disease. PLOS ONE 2012;7:e47305.

21. Sethi S, Evans N, Grant BJ, et al. New strains of bacteria and exacerbations of chronic obstructive pulmonary disease. $N$ Engl J Med 2002;347:465-71.

22. Rosell A, Monsó E, Soler N, et al. Microbiologic determinants of exacerbation in chronic obstructive pulmonary disease. Arch Intern Med 2005;165:891-7.

23. Patel IS, Seemungal TA, Wilks M, et al. Relationship between bacterial colonisation and the frequency, character, and severity of COPD exacerbations. Thorax 2002;57:759-64.

24. Wilkinson TM, Patel IS, Wilks M, et al. Airway bacterial load and FEV1 decline in patients with chronic obstructive pulmonary disease. Am J Respir Crit Care Med 2003;167:1090-5

25. Marin A, Garcia-Aymerich J, Sauleda J, et al. Effect of bronchial colonisation on airway and systemic inflammation in stable COPD. COPD 2012;9:121-30.

26. Sethi S, Sethi R, Eschberger K, et al. Airway bacteria concentrations and exacerbations of chronic obstructive pulmonary disease. Am J Respir Crit Care Med 2007;176:356-61.

27. Global Initiative for Chronic Obstructive Lung Disease, Inc. Global strategy for the diagnosis, management, and prevention of COPD (revised 2011). http://www.goldcopd.org/uploads/users/files/GOLD Report_2011_Feb21.pdf (accessed 12 Feb 2014)

28. Anthonisen NR, Manfreda J, Warren CP, et al. Antibiotic therapy in exacerbations of chronic obstructive pulmonary disease. Ann Intern Med 1987;106:196-204.

29. Wilkinson TM, Donaldson GC, Hurst JR, et al. Early therapy improves outcomes of exacerbations of chronic obstructive pulmonary disease. Am J Respir Crit Care Med 2004;169:1298-303.

30. BAPEN. The MUST toolkit. http://www.bapen.org.uk/ screening-for-malnutrition/must/must-toolkit/the-must-itself (accessed 12 Feb 2014).

31. Jones PW, Brusselle G, Dal Negro RW, et al. Properties of the COPD assessment test in a cross-sectional European study. Eur Respir J 2011;38:29-35.

32. Nouri FM, Lincoln NB. An extended activities of daily living scale for stroke patients. Clin Rehabil 1987;1:301-5.

33. Wilson MM, Thomas DR, Rubenstein LZ, et al. Appetite assessment: simple appetite questionnaire predicts weight loss in community-dwelling adults and nursing home residents. Am J Clin Nutr 2005;82:1074-81.

34. The EuroQol Group. EuroQol-a new facility for the measurement of health-related quality of life. Health Policy 1990;16:199-208.

35. Celli BR, Cote CG, Marin JM, et al. The body-mass index, airflow obstruction, dyspnea, and exercise capacity index in chronic obstructive pulmonary disease. N Engl J Med 2004;350:1005-12.

36. Hurst JR, Wedzicha JA. An introduction to conducting COPD exacerbation research. Respir Med 2009;5:38-44

37. Vestbo J, Anderson W, Coxson HO, et al. Evaluation of COPD longitudinally to identify predictive surrogate end-points (ECLIPSE). Eur Respir J 2008;31:869-73.

38. Regan EA, Hokanson JE, Murphy JR, et al. Genetic epidemiology of COPD (COPDGene) study design. COPD 2010;7:32-43.

39. Woodruff PG. Novel outcomes and end points: biomarkers in chronic obstructive pulmonary disease clinical trials. Proc Am Thorac Soc 2011;8:350-5

40. Beasley V, Joshi PV, Singanayagam A, et al. Lung microbiology and exacerbations in COPD. Int $J$ Chron Obstruct Pulmon Dis 2012;7:555-69.

41. Mackay AJ, Hurst JR. COPD exacerbations: causes, prevention, and treatment. Med Clin North Am 2012;96:789-809.

42. Global Initiative for Chronic Obstructive Lung Disease, Inc. Global strategy for the diagnosis, management, and prevention of COPD (updated 2013). http://www.goldcopd.org/uploads/users/files/GOLD_ Report_2013_Feb20.pdf (accessed 12 Feb 2014).

43. Sethi S, Jones PW, Theron MS, et al. Pulsed moxifloxacin for the prevention of exacerbations of chronic obstructive pulmonary disease: a randomized controlled trial. Respir Res 2010;11:10.

44. Albert RK, Connett J, Bailey WC, et al. Azithromycin for prevention of exacerbations of COPD. N Engl J Med 2011;365:689-98. 


\section{Correction}

Bourne S, Cohet C, Kim V, et al. Acute Exacerbation and Respiratory InfectionS in COPD (AERIS): protocol for a prospective, observational cohort study. BMJ Open 2014;4:e004546. The penultimate author of this paper should read Stuart C Clarke.

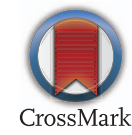

BMJ Open 2015;5:e004546. doi:10.1136/bmjopen-2013-004546corr1 